\title{
The Persistence of Opioid Use Following Surgical Admission: An Australian Single-Site Retrospective Cohort Study
}

\author{
Felicity Veal (D) \\ Angus Thompson' \\ Samuel Halliday ${ }^{2}$ \\ Peter Boyles ${ }^{2}$ \\ Chris Orlikowski ${ }^{3}$ \\ Luke Bereznicki ${ }^{\prime}$ \\ 'Unit for Medication Outcomes Research \\ \& Education (UMORE), School of \\ Pharmacy and Pharmacology, University \\ of Tasmania, Hobart, Tasmania, Australia; \\ ${ }^{2}$ Department of Health, Hobart, \\ Tasmania, Australia; ${ }^{3}$ Federal Pain Clinic, \\ Hobart, Tasmania, Australia
}

This article was published in the following Dove Press journal: Journal of Pain Research

Background: Acute pain is common following surgery, with opioids frequently employed in its management. Studies indicate that commencing an opioid during a hospital admission increases the likelihood of long-term use. This study aimed to identify the prevalence of opioid persistence amongst opioid-naïve patients following surgery as well as the indication for use. Methods: A retrospective review of patients who underwent a surgical procedure at the Royal Hobart Hospital, Tasmania, Australia, between August and September 2016 was undertaken. Patients were linked to the Tasmanian real-time prescription monitoring database to ascertain if they were subsequently dispensed a Schedule 8 opioid (morphine, codeine oxycodone, buprenorphine, hydromorphone, fentanyl, methadone, or tapentadol) and the indication for use.

Results: Of the 3275 hospital admissions, 1015 opioid-naïve patients were eligible for inclusion. Schedule 8 opioids were dispensed at or within 2 days of discharge in $41.7 \%$ of admissions. Thirty-nine $(3.9 \%)$ patients received prescribed opioids 2-months postdischarge; $1.8 \%$ of the patients were approved by State Health to be prescribed Schedule 8 opioids regularly for a chronic condition at 6 months, and $1.3 \%$ received infrequent or oneoff prescriptions for Schedule 8 opioids at 6 months. Thirteen $(1.3 \%)$ patients continued Schedule 8 opioids for at least 6 months following their surgery, with the indication for treatment either related to the surgery or the condition which surgery was sought for.

Conclusion: This study found that there was a low rate of Schedule 8 opioid persistence following surgery, indicating post-surgical pain is not a significant driver for persistent opioid use.

Keywords: opioids, post-operative, persistence, prescribing

\section{Background}

Acute pain is common and expected following a surgical procedure. ${ }^{1,2}$ Opioids are frequently supplied following surgery to manage pain and patients are often discharged home with opioids intended for short-term use to assist with their acute post-surgical pain management. ${ }^{3}$ One Australia study found that $82 \%$ of the patients who underwent orthopaedic surgery or neurosurgery were discharged on an opioid. ${ }^{4}$ International studies report post-surgical opioid dispensing rates vary from $7.1 \%{ }^{5}$ to $80.0 \%{ }^{6}$

Poor acute pain management increases the risk of post-operative complications, length of hospital admission, likelihood of readmission ${ }^{7-10}$ as well as the risk of persistent post-surgical pain. ${ }^{7}$ In line with the growing awareness of the importance
Unit for Medication Outcomes Research

\& Education (UMORE), School of

Pharmacy and Pharmacology, University

of Tasmania, Private Bag 26, Hobart,

Tasmania 700I, Australia

Tel +6I 362262312

Fax +6I 362267627

Email Felicity.Veal@utas.edu.au 
of acute pain management, it has been reported that between 2004 and 2012, there have been increases in both the proportion of low-risk surgical patients receiving an opioid and the mean opioid dose prescribed. ${ }^{6}$ The rate of opioid persistence following short-stay surgery, which is generally considered to result in minimal long-term pain, was $10 \%$ at 1 year, and those prescribed an opioid post-operatively were more likely to still be taking an opioid at 12 months. ${ }^{5}$ Merely receiving an opioid on hospital discharge, irrespective of surgery, has been associated with an increased the likelihood of chronic opioid use in previously opioid-naïve patients. ${ }^{5,11-14}$ These studies did not ascertain the cause or source of pain for which the opioid was prescribed following discharge.

There has been increasing concern about long-term opioid use, due to the risk of adverse events and accidental death. ${ }^{15}$ To date, two studies ${ }^{16,17}$ have reviewed post-surgical opioid persistence in Australia; one in a subset of Australians (Veterans) which found a persistence rate of $3.1 \%$ at 90 days ${ }^{16}$ and the other study reviewing patients undergoing elective surgery at a private hospital, which found a persistence rate of $10.5 \%$ at 90 days. However, these studies were unable to ascertain the cause or source of pain for long-term opioids. Consequently, this study aims to provide further detailed information about the prevalence of opioid use for pain related to surgery or the condition for which surgery sought, and thus inform clinical practice.

\section{Methods}

A retrospective cohort study of patients discharged from the Royal Hobart Hospital (RHH), Tasmania, Australia following a surgical procedure was undertaken. All eligible patients who were discharged from a surgical unit at the RHH between 1 August and 30 September 2016 were included in the study.

In Tasmania, all Schedule 8 opioid (morphine, codeine, oxycodone, buprenorphine, hydromorphone, fentanyl, methadone, or tapentadol) dispensed by hospital and community pharmacies is recorded through a real-time prescription monitoring system, called Drugs and Poisons Information System (DAPIS). Inpatient provision of opioids is not recorded in DAPIS. This system is administered by the Tasmanian Department of Health and is used to monitor and authorise prescribing and dispensing of Schedule 8 medication (and as of February 2018 Schedule 4 opioids, ie, tramadol and combination codeine products). If a patient is supplied a Schedule 8 opioid regularly for a prescribed period (usually exceeding 2 months), a legal authority is required from the Department of Health. ${ }^{18}$ Regular opioid use for more than 2 months without a legal authority is flagged by DAPIS and the Department of Health sends the prescriber an urgent reminder that an authority application is required immediately. The approval application includes the opioid, strength, daily dose, and source or cause of pain that requires an opioid to be prescribed.

Eligible inpatients were identified through discharge lists (which included patient demographics, the operation performed and presenting complaint) from all surgical units at the RHH. Every patient was reviewed using the digital medical record (DMR) to exclude paediatric patients, patients that did not undergo surgery or did not undergo an eligible procedure. Ophthalmic and dental procedures were excluded. Additionally, diagnostic procedures such as endoscopy, cystoscopy, colposcopy, colonoscopy, large loop excision of the transformation zone (LLETZ), prostate biopsy, as well as other less invasive producers such as dilation and curettage, vasectomy, angiograms, and procedures that required only local anaesthetics were also excluded. Surgical procedures that were outsourced to one of the local private hospitals were also excluded from the analysis. Patients prescribed preoperative long-term Schedule 8 opioids (defined as having an authority approved or pending with the Tasmanian Department of Health, at the time of the surgery and having had at least one dispensing for an opioid in the 2 months preceding their surgery) were also excluded.

The DAPIS records of eligible patients were then reviewed. This identified if they had been discharged from hospital with, or were dispensed a prescription for, a Schedule 8 opioid within 2 days of their discharge. We also identified dispensing of opioids at two subsequent time points; the first 2 months after discharge (this is the time point used by the Poisons Act 1971 to define chronic opioid use), the second approximately 6 months after discharge. Because the daily dose is not recorded on DAPIS for dispensing events (only when authorities are received), assessment of a supply at 2 and 6 months was undertaken by reviewing prescriptions dispensed within 2 weeks of the date of interest, and using standard dosing it was estimated if the patient was likely to be still taking this medication. In addition, for those who were receiving an opioid at 6 months, their records were further reviewed to identify the indication for use and whether an authority for long term prescribing had been issued. The daily oral morphine equivalent (MEQ/d) was calculated for patients with an approval for an opioid. ${ }^{19}$ 
Analysis was performed using SPSS version 24 for Windows (SPSS Inc., Chicago, IL, USA). Results were described using medians and interquartile ranges (IQR). Univariate analysis was undertaken using Chi-square and Mann-Whitney $U$-tests. A p-value of $<0.05$ was considered statistically significant. Patients who had more than one admission were only included once in the long-term followup. This study was approved by the Tasmanian Health and Medical Human Research Ethics Committee (HREC), Reference No: H0015744, and a consent waiver was granted by the HREC. This was due to the data being retrospective, creating impracticalities with contacting potential participates to gain consent. Additionally, participants were unaware of their participation and there was no risk to the patient or changes in treatment due to this study. All data once linked was deidentified to ensure patient confidentiality was maintained. This study was compliant with the Declaration of Helsinki.

\section{Results}

Figure 1 provides information about the flow of patients through the study. There were 3275 surgical admissions during the research time frame, of which 1015 admissions for 1004 patients were considered eligible. Of the 11 patients who had multiple admissions, all except one were related to the initial operation or diagnosis. Four of these patients were prescribed opioids at discharge, and only one had a prescription dispensed for a Schedule 8 opioid at 2 months which was provided on discharge from hospital for a subsequent surgical procedure. The median age was 47 years (IQR: $31-63$ years), and $51.1 \%$ of the cohort were female. There were 419 admissions $(41.7 \%)$ that resulted in a patient being discharged with or receiving a prescription for a Schedule 8 opioid within 2 days of discharge. Patients who received an opioid were slightly younger than those who did not (45 years (IQR 31-60 years) vs 49 (IQR $31-63$ years) $p=0.02$ ), and there was no significant difference between the proportion of females and males receiving opioids $(52.6 \%$ vs $47.4 \% \mathrm{p}=0.41)$.

The most commonly supplied Schedule 8 opioid at or soon after discharge was immediate-release oxycodone, which was dispensed to 388 patients by itself $(92.8 \%)$ and in further 18 patients $(4.3 \%)$ in combination with a second Schedule 8 opioid. Other medications dispensed at or in the immediate 2 days after discharge included modified-release oxycodone, ${ }^{6}$ buprenorphine, ${ }^{4}$ tapentadol, ${ }^{2}$ morphine, ${ }^{2}$ and codeine phosphate. ${ }^{1}$ It was not possible to record tramadol

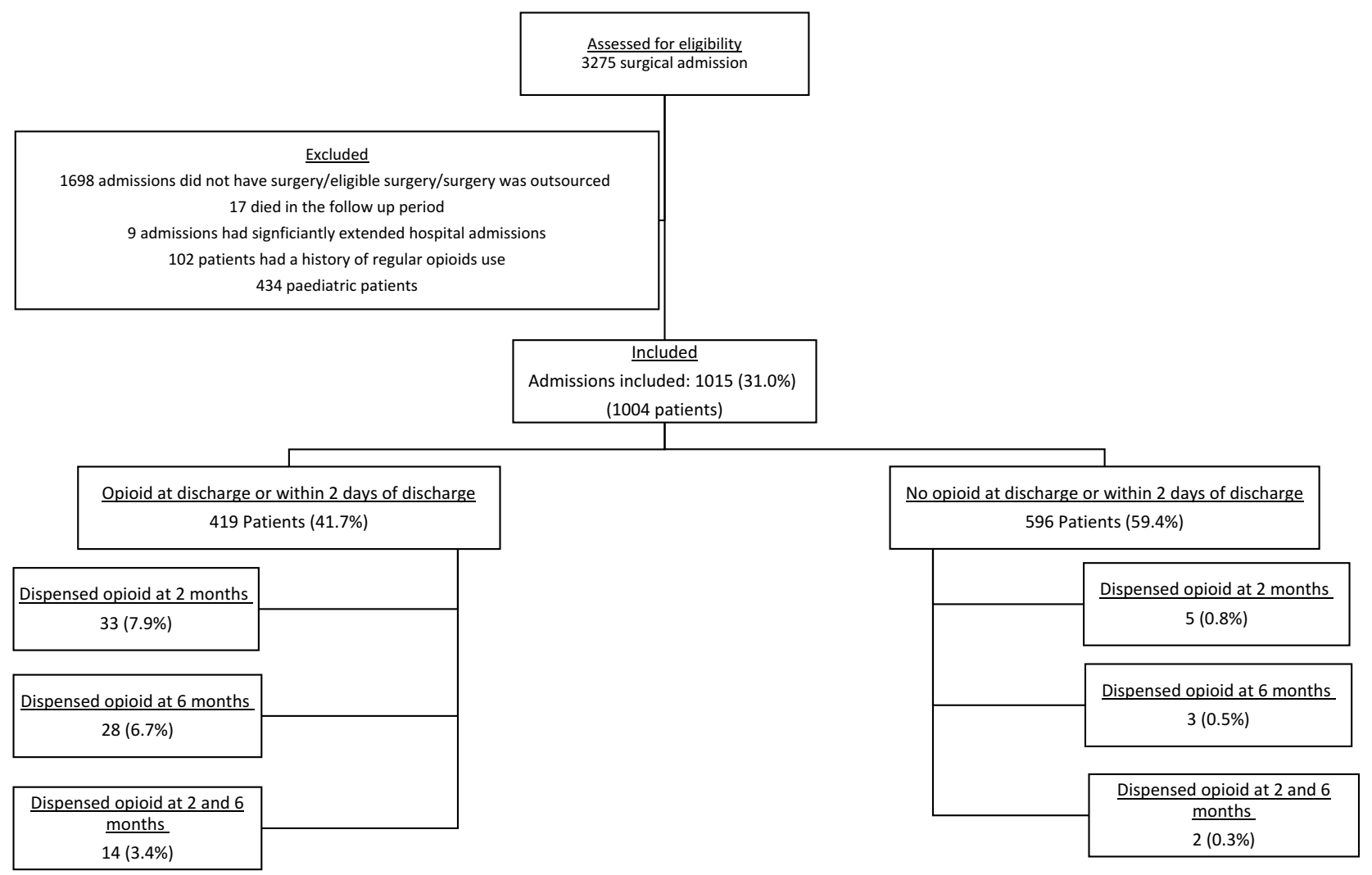

Figure I Use of opioids by post-surgical patients. 
or combination analgesics containing codeine, as they were not included in DAPIS at the time of data collection.

The number of dispensings against the mean number of IR oxycodone tablets (the most commonly prescribed opioid) provided across all supplies as well as the MEQ for all Schedule 8 opioids dispensed in the first 2 months are summarised in Table 1 . Most patients $(n=317 ; 75.7 \%)$ received only one supply of an opioid at discharge or within the following 2 days of discharge; $42(10.0 \%)$ had two supplies; 21 (5.0\%) had three supplies and $34(8.1 \%)$ had four or more supplies within the first 2 months. Of the 97 patients who were dispensed an opioid on more than one occasion, $27(27.8 \%)$ had their last prescription dispensed within 7 days of discharge, with a further 20 $(20.6 \%)$ patients having their last prescription dispensed within 2 weeks of their discharge.

At approximately 2 months after discharge, 38 (3.8\%) patients had a prescription for a Schedule 8 opioid dispensed. Thirty-three of these patients had received opioids in the 2 days after discharge. At 6 months, 31 (3.1\%) patients were dispensed a prescription for a Schedule 8 opioid. Thirteen were dispensed infrequent or one-off Schedule 8 opioid prescription, while 18 patients were dispensed regular Schedule 8 opioids and the prescriber had applied for an authority for continued opioid prescription. Of these 18 patients, 16 were also dispensed opioids at 2 months and 14 patients were dispensed opioids at all three time points (post-discharge, 2, and 6 months).

Of the 16 patients who were taking opioids at both 2 and 6 months, 4 were unrelated to surgery or the surgical condition; and 12 were either related to the condition that required surgery $(n=5)$ eg, metastatic cancer pain following surgery to remove cancer, or as a consequence of surgery $(n=7)$ eg,

Table I The Number of Dispensings Against the Average Amount of Opioid Prescribed in the First 2 Months Following Surgery ( $n=419$ Patients)

\begin{tabular}{|c|c|c|}
\hline & $\begin{array}{l}\text { Mean Number of IR } \\
\text { Oxycodone Tablets } \\
\text { Provided, n (SD) }\end{array}$ & $\begin{array}{l}\text { Average MEQ of All } \\
\text { Opioids Dispensed, } \\
\text { MEQ mg (SD) }\end{array}$ \\
\hline $\begin{array}{l}\text { I dispensing } \\
\text { (within two } \\
\text { days of } \\
\text { discharge) }\end{array}$ & $16(6.0)$ & I 30.2 (70.5) \\
\hline 2 dispensings & $36(11.3)$ & $304.8(174.3)$ \\
\hline 3 dispensings & $58(34.0)$ & $564.5(236.2)$ \\
\hline $\begin{array}{l}4 \text { or more } \\
\text { dispensings }\end{array}$ & $76(46.0)$ & $923.2(922.1)$ \\
\hline
\end{tabular}

Table 2 Indication for Long-Term Opioid and Type of Surgery

\begin{tabular}{|l|l|l|}
\hline Pain & Surgical Category & $\begin{array}{l}\text { Number of } \\
\text { Patients }\end{array}$ \\
\hline $\begin{array}{l}\text { Back/neck pain } \\
\text { Abdominal pain/ } \\
\text { bowel cancer }\end{array}$ & $\begin{array}{l}\text { Back/neck surgery } \\
\text { Lurgery }\end{array}$ & 3 \\
Tumour/metastasis & Craniotomy & 3 \\
$\begin{array}{l}\text { Phantom pain } \\
\text { Non-healing wound } \\
\text { pain }\end{array}$ & Post toe/leg amputation & 2 \\
Abdominal pain & Wound debridement & 1 \\
Chest pain & Laparotomy & 1 \\
\hline
\end{tabular}

failed back surgery. For the two applications where the patient was not taking opioids at 2 months, one was associated with the condition for which they sought surgery for and the other was for an unrelated condition. Three applications cited multiple indications for the opioids including the surgery or condition for which surgery was sought and three authorities were for metastatic cancer associated with their surgery. The indications for long-term opioid prescribing for those related to the surgical procedure or condition requiring surgery are presented in Table 2.

For those patients where the opioid(s) were prescribed due to the surgery or the surgical condition, the median $\mathrm{MEQ} / \mathrm{d}$ was $16 \mathrm{mg}$ (range 5-165 mg MEQ/d). Two patients were prescribed daily doses exceeding $50 \mathrm{mg} \mathrm{MEQ} / \mathrm{d}$. There were 19 opioids approved for 13 patients, 8 patients prescribed oxycodone immediate-release tablets, with other approved opioids including oxycodone/naloxone modified release, ${ }^{7}$ buprenorphine patches, ${ }^{1}$ morphine modified release capsules, ${ }^{1}$ methadone tablets, ${ }^{1}$ and tapentadol modified-release tablets. ${ }^{1}$

\section{Discussion}

This study indicates that only a small proportion $(1.3 \%)$ of patients, who were opioid naïve prior to surgery, were taking opioids 6 months following their surgical discharge, with the indication for use either related to the surgery or the condition for which surgery was sought. With the exception of two patients with an opioid intake exceeding $50 \mathrm{mg} \mathrm{MEQ} / \mathrm{d}$, the majority received only low-moderate dose opioids (in terms of MEQ/day) potentially indicating that prescribers are heeding recommendations regarding the use of the lowest effective dose of opioids.

Although this is the third Australian study that we are aware of that has reviewed the persistence of opioids in opioid-naïve patients undergoing a surgical procedure, but 
in contrast to previous research, this study determined the source or site of pain that necessitated long-term prescribing of Schedule 8 opioids. The persistence rates identified in this study are lower than both recent Australian studies ${ }^{16,17}$ and a number of other international studies. ${ }^{5,6,12,13}$ However, our results are consistent with a recent Danish study ${ }^{13}$ which found an increase of $1.4 \%$ (at 1 year) from baseline. Potentially, the lower rates of persistence identified in this study may have been associated with three aspects: 1) our study was able to determine the reasons for long-term opioids rather than all cause prescribing; 2) our study was unable to assess the persistence of Schedule 4 opioids; 3) the surgical indication in some of the previous studies ${ }^{14}$ focussed on surgeries more likely to result in pain, eg, orthopaedic or neurology.

This study also found that many patients were dispensed Schedule 8 opioids at or immediately following discharge ( $41.7 \%$ of the surgical admissions) which was consistent with Clark and colleagues ${ }^{14}$ who found $49.2 \%$ of the patients were discharged with an opioid. In our study, over three-quarters of these patients received only one supply and few received further supplies of opioids beyond 2 weeks after their discharge. This is consistent with the study conducted by Roughead and colleagues, which reported that $70 \%$ of the patients had ceased opioids by 14 days. ${ }^{16}$ Additionally, the quantity of medication supplied for patients receiving only one post-discharge prescription of Schedule 8 opioids, was on average less than a standard box (quantity 20) of immediate-release oxycodone, indicating that prescribers were not providing excessive quantities of opioids in each prescription.

Our finding of expedient cessation of opioids, as well as the low rates of persistence, suggests that opioids dispensed following surgery are not a major contributor to long-term opioid prescribing. However, this study was unable to determine the utilisation of tramadol or combination analgesics containing codeine following hospital discharge and this is likely to result in an underestimate of the likelihood of opioid persistence, with a previous study identifying patients commenced on tramadol following surgery were as likely, if not more likely to persistent taking opioids long term. ${ }^{20}$

There are some limitations with this study, including the use of only one site (albeit the largest hospital in Tasmania) and a short ( 2 months) recruitment period. Two months were selected as one of the follow-up time points to be reviewed because the Poisons Act 1971 defines this as the time when opioid use becomes chronic. However, it is noted that other studies have reviewed use up to 90 days to one post-operative year ${ }^{21}$ which may make comparison of persistent rates between studies difficult. Further research should be undertaken to determine the long-term use of other opioids, namely tramadol and codeine combination products following surgery to complement this study.

\section{Conclusion}

This study found there was a low rate of Schedule 8 opioid persistence following surgery. Only $1.3 \%$ of opioid-naïve patients were prescribed Schedule 8 opioids for at least 6 months following their surgery, with the indication for treatment either related to the surgery or the condition which surgery was sought for. To complete the picture further research is needed to identify the prevalence and persistence of tramadol and codeine containing analgesic use following surgery.

\section{Acknowledgment}

We thank Mrs Jan Taylor for her assistance in data collection. This research was supported by a grant from the Royal Hobart Hospital Research Fund (RHHRF) (no. 17-103).

\section{Disclosure}

Professor Bereznicki reports personal fees from Boehringer Ingelheim Pty Ltd, grants from Aspen Pharmacare Australia, outside the submitted work. Dr Chris Orlikowski has received funding from Seqirus for speaking at educational meetings, outside of the submitted work. The authors report no other conflicts of interest in this work.

\section{References}

1. Vadivelu N, Mitra S, Narayan D. Recent advances in postoperative pain management. Yale J Biol Med. 2010;83(1):11-25.

2. Kehlet H, Jensen TS, Woolf CJ. Persistent postsurgical pain: risk factors and prevention. Lancet. 2006;367(9522):1618-1625. doi:10.10 16/S0140-6736(06)68700-X

3. Macintyre PE, Huxtable CA, Flint SLP, Dobbin MDH. Costs and consequences: a review of discharge opioid prescribing for ongoing management of acute pain. Anaesth Intensive Care. 2014;42(5):5 58-574. doi:10.1177/0310057X1404200504

4. Stanley B, Norman AF, Collins LK, et al. Opioid prescribing in orthopaedic and neurosurgical specialties in a tertiary hospital: a retrospective audit of hospital discharge data. ANZ J Surg. 2018;88 (11):1187-1192. doi:10.1111/ans.14873

5. Alam A, Gomes T, Zheng H, Mamdani MM, Juurlink DN, Bell CM. Long-term analgesic use after low-risk surgery: a retrospective cohort study. Arch Intern Med. 2012;172:425-430. doi:10.1001/archinternmed. 2011.1827

6. Wunsch H, Wijeysundera DN, Passarella MA, Neuman MD. Opioids prescribed after low-risk surgical procedures in the United States, 2004-2012. JAMA. 2016;315(15):1654-1657. doi:10.1001/jama.2016. 0130 
7. Macrae WA. Chronic post-surgical pain: 10 years on. $B r J$ Anaesth. 2008;101(1):77-86. doi:10.1093/bja/aen099

8. Niraj G, Rowbotham DJ. Persistent postoperative pain: where are we now? Br J Anaesth. 2011;107(1):25-29. doi:10.1093/bja/aer116

9. Carr DB, Goudas LC. Acute Pain. Lancet. 1999;353(9169):20 51-2058. doi:10.1016/S0140-6736(99)03313-9

10. Twersky R, Fishman D, Homel P. What happens after discharge? Return hospital visits after ambulatory surgery. Anesth Analg. 1997;84(2):319-324. doi:10.1213/00000539-199702000-00014

11. Calcaterra SL, Yamashita TE, Min SJ, Keniston A, Frank JW, Binswanger IA. Opioid prescribing at hospital discharge contributes to chronic opioid use. J Gen Intern Med. 2015;9.

12. Carroll I, Barelka P, Wang CK, et al. A pilot cohort study of the determinants of longitudinal opioid use after surgery. Anesth Analg. 2012;115:694-702. doi:10.1213/ANE.0b013e31825c049f

13. Simoni AH, Nikolajsen L, Olesen AE, Christiansen CF, Pedersen AB. Opioid use after hip fracture surgery: a Danish nationwide cohort study from 2005 to 2015. Eur J Pain. 2019;23(7):13 09-1317. doi:10.1002/ejp.1392

14. Clark H, Soneji N, Ko DT, Yun L, Wijeysundera DN. Rates and risk factors for prolonged opioid use after major surgery: population based cohort study. BMJ. 2014;348:g1251. doi:10.1136/bmj. g1251

15. Hah JM, Bateman BT, Ratliff J, Curtin C, Sun E. Chronic opioid use after surgery: implications for perioperative management in the face of the opioid epidemic. Anesth Analg. 2018;125(5):1733-1740. doi:10.1213/ANE.0000000000002458
16. Roughead EE, Lim R, Ramsay E, Moffat AK, Pratt NL. Persistence with opioids post discharge from hospitalisation for surgery in Australian adults: a retrospective cohort study. BMJ Open. 2019;9: e023990. doi:10.1136/bmjopen-2018-023990

17. Stark N, Kerr S, Stevens J. Prevalence and predictors of persistent post-surgical opioid use: a prospective observational cohort study. Anaesth Intensive Care. 2017;45(6):700-767. doi:10.1177/0310057X17 04500609

18. Poisons Act 1971, Part VA; 2019.

19. Nielsen S, Degenhardt L, Hoban B, Gisev N Comparing opioids: a guide to estimating oral morphine equivalents (OME) in research. Technical report No. 329. Sydney; National Drug and Alchol Research Centre, University of New South Wales; 2014.

20. Thiels CA, Habermann EB, Hooten WM, Jeffery MM. Chronic use of tramadol after acute pain episode: cohort study. BMJ. 2019;365. doi:10.1136/bmj.11849.

21. Kent ML, Hurley RW, Odera GM, et al. American Society for Enhanced Recovery and Perioperative Quality Initiative-4 Joint Consensus Statement on Persistent Postoperative Opioid Use: definition, Incidence, Risk Factors, and Health Care System Initiatives. Anesth Analg. 2019;129(2):543-552. doi:10.1213/ANE.0000000000003941
Journal of Pain Research

\section{Publish your work in this journal}

The Journal of Pain Research is an international, peer reviewed, open access, online journal that welcomes laboratory and clinical findings in the fields of pain research and the prevention and management of pain. Original research, reviews, symposium reports, hypothesis formation and commentaries are all considered for publication. The manuscript

\section{Dovepress}

management system is completely online and includes a very quick and fair peer-review system, which is all easy to use. Visit http:// www.dovepress.com/testimonials.php to read real quotes from published authors. 